\title{
Usage and Barriers to Use of Latrines in a Ghanaian Peri-Urban Community
}

\author{
Peter A. Obeng • Bernard Keraita • \\ Sampson Oduro-Kwarteng • Henrik Bregnhøj • \\ Robert C. Abaidoo • Esi Awuah • Flemming Konradsen
}

Received: 22 October 2014 / Accepted: 19 January 2015 /Published online: 11 February 2015

(C) Springer International Publishing Switzerland 2015

\begin{abstract}
Regular usage of latrines is crucial to public health. This study was conducted in a Ghanaian peri-urban setting to understand the factors that influence the usage of household and communal latrines and to discuss potential interventions to address existing barriers to regular usage. Data was collected using household survey questionnaires orally administered to 189 and 283 respondents with access to private and communal latrines respectively, five focus group discussions with gender and age groups, as well as observations at latrines. It was found that only $15 \%$ of households had access to latrines at home while the rest depended on communal latrines or practised open defecation. The ventilated improved pit latrine was the commonest technology used by $47 \%$ of households with private latrines. The residents ranked safety and privacy as the most important factors that influenced their decision to use any latrine. For private latrines, desludging challenges $(14 \%)$ and intense odour $(7 \%)$ were the most significant technical barriers while the most significant non-technical barriers were lack of immediate access when the latrine is locked or busy (28\%). For communal latrines, the major technical barrier was intense odour $(23 \%)$ while the major non-technical barriers were distance to latrines $(28 \%)$, user fees $(21 \%)$ and unhygienic conditions $(7 \%)$. Regular latrine usage in the study setting may be enhanced by technical support to address desludging challenges and control odour in latrines, as well as social interventions to make communal latrines affordable and more hygienic.
\end{abstract}

P. A. Obeng $(\bowtie) \cdot$ S. Oduro-Kwarteng $\cdot$ E. Awuah

Civil Engineering Department, Kwame Nkrumah University of Science and Technology, Kumasi, Ghana e-mail: obengpeter@yahoo.com

P. A. Obeng

Water and Sanitation Unit, Chemistry Department, University of Cape Coast, Cape Coast, Ghana

B. Keraita $\cdot$ H. Bregnhøj $\cdot$ F. Konradsen

Department of International Health, Immunology and Microbiology, University of Copenhagen, Copenhagen, Denmark

R. C. Abaidoo

Department of Theoretical and Applied Biology, Kwame Nkrumah University of Science and Technology, Kumasi, Ghana 
Keywords Sanitation $\cdot$ Latrines $\cdot$ Usage $\cdot$ Barriers $\cdot$ Peri-urban $\cdot$ Ghana

\section{Introduction}

Access to improved latrines at home and in public places is a crucial defence against faecal-oral transmission of pathogenic agents to humans and the environment (Mara et al. 2010; Kvarnstrom et al. 2011). The case of low-income peri-urban and urban slums is of much greater concern due to their frequent association with vector-borne diseases, bacterial infections and contamination of drinking water amidst a rapidly growing population (Nakagawa et al. 2006; Paterson et al. 2007; Sidhu and Toze 2009). Nevertheless, the impact of latrine provision on public health is dependent on the response of the intended users, especially their commitment to regularly use and maintain the facility. To ensure regular latrine usage, the choice of technology, the design and construction of facilities, as well as their operation and maintenance should be directly linked to the defecation practices, preferences and cultural values of the intended users (Garfi and Ferrer-Marti 2011; Olschewski 2013). It is, therefore, crucial to understand the factors that influence latrine usage and the barriers to regular use in any cultural and socio-economic context. Understanding of such factors is required to guide the development of technical and social interventions that are consistent with and likely to stimulate local drivers of latrine usage.

The Joint Monitoring Programme (JMP) of the World Health Organisation (WHO) and UNICEF defines improved sanitation as "a sanitation system in which excreta are disposed of in such a way that they reduce the risk of faecal-oral transmission to its users and the environment' (UN Millennium Project, 2005; p. 29). Specific types of improved sanitation facilities recognised by the JMP include flush or pour-flush latrine, pit latrine with a slab, ventilated improved pit (VIP) latrine and the composting toilet (Karnib 2014). To be accepted as 'improved', a sanitation facility is required to be used exclusively by only one household. In Ghana, only $14 \%$ of the population have access to improved sanitation as against an MDG target of $54 \%$ set for 2015 (JMP 2014). The proportion of Ghana's population depending on shared sanitation, including public toilets (59\%), is the highest in the world (JMP 2014). According to the JMP, $19 \%$ of Ghanaians practise open defecation while $8 \%$ depend on various forms of unimproved sanitation options such as bucket latrines. In terms of technology mix, nearly half of Ghanaian households depend on dry sanitation systems such as the simple pit and ventilated improved pit latrines while $10 \%$ depend on wet or flush on-site systems (GSS 2008). Sewerage is only piloted in parts of the country and covers only about $3 \%$ of Ghanaian households (GSS 2013). To improve the status of sanitation in the country, the government has over the last decade introduced a number of policies including the adoption of the community-led total sanitation (CLTS) approach and a strong advocacy for households in residential areas to acquire their own toilet facilities, with public sanitation facilities only recommended for transport terminals and other commercial centres (MLGRD 2010a).

In spite of the recent efforts to improve sanitation in Ghana, the above statistics show that progress towards the MDG has been slow, with some policies simply not yielding the anticipated results. For instance, the use of hygiene education and subsidies to increase household latrine uptake under the Rural Water Supply Programme IV (2005-2009), implemented in selected districts in the Ashanti Region, failed to generate the expected response from the beneficiaries (Ampadu-Boakye et al. 2011). In each of the participating districts, 226 latrines were allocated to be constructed with $50 \%$ subsidy. However, in some districts, less than $5 \%$ of the allocated latrines were actually constructed under the programme. Among the reasons attributed to the poor response to the intervention in these districts was the failure to 
conduct background studies in the communities prior to the start of the project. Such background studies usually include household preferences and willingness-to-pay, which are useful for predicting community response to such programmes (Whyte 1986; Ayele 2005). Beside these, understanding the reasons why people avoid or are dissatisfied with existing facilities would also offer a useful insight into how to design the technical and social aspects of the interventions in order to make them attractive to the targeted beneficiaries.

With the limited sanitation facilities in Ghana, studies and official reports have identified some technical and non-technical factors that affect their regular usage, level of service and user satisfaction. These include design and construction, mechanisms to dislodge excreta, siting of facilities and user behaviour (Jenkins and Scott 2007; MLGRD 2010b; Appiah and Oduro-Kwarteng 2011). However, the reaction of people to these technical and operational factors may vary among the different cultures and socio-economic characteristics across the country (Dittmer 2009; Olschewski 2013).

This study was conducted in the coastal peri-urban setting of Ghana to understand the factors influencing latrine usage and the barriers or constraints that discourage regular use of existing household and communal latrines. The paper also discusses potential interventions to improve latrine usage in such settings.

\section{Methods}

\subsection{Study Area}

The study was conducted in Prampram, a coastal peri-urban community geographically located between $5^{0} 45^{\prime}-6^{0} 05^{\prime} \mathrm{N}$ and $0^{0} 05^{\prime}-0^{0} 20^{\prime} \mathrm{W}$ along the coast of the Gulf of Guinea in the Greater Accra Region of Ghana. It is the administrative capital of the Ningo-Prampram District. With a population of 7800 and 1635 households (DHRC 2012), the town is growing rapidly partly due to its proximity to Accra, the national capital. The main occupations of the residents are fishing, farming and trading.

The state of water supply and environmental sanitation in Prampram is similar to the trend in many Ghanaian peri-urban towns. The main source of water supply is piped water provided by the Ghana Water Company Limited. However, actual flow of water into the community occurs only once or twice per week. Many residents rely on water vendors who receive bulk supply from tanker trucks at a substantially higher price.

No sewerage infrastructure exists in the community, so all residents depend on on-site sanitation technologies for excreta collection and disposal. As in other Ghanaian traditional communities, the practice of the extended family system and multiple tenancies of houses encourages the sharing of latrines on compounds. Generally, latrine coverage is low as compared to national averages. Baseline studies conducted in the study area as part of the Sustainable Sanitation (SUSA) Ghana project reported that only $8 \%$ of respondents had access to a latrine used exclusively by one household; $11 \%$ had access to shared latrines on their compound; $17 \%$ used communal latrines while over $50 \%$ practised open defecation (Spencer 2012).

\subsection{Data Collection Methods}

\subsubsection{Focus Group Discussions}

Five focus group discussions were held. They comprised two male and two female groups, with each gender group divided into adults and youths between the ages of 13 and 17 years. 
The fifth group was made up of communal latrine caretakers that were responsible for the operation and maintenance of communal latrines including the collection of user fees. Each of the gender groups was made up of 8-10 participants. The communal latrine caretakers' group was made up of five caretakers ( 2 males, 3 females) from 5 out of 7 communal latrines in the community.

At each meeting, the participants discussed the factors they perceived to encourage or discourage them from using a particular latrine, whether private or public. The factors mentioned by the groups in the open discussion were recorded under themes that were preidentified in literature. The groups then ranked the relative importance of the themes as shown in Table 3. Where a group did not mention any factor associated with a particular theme, such themes were introduced to them and included in the ranking. This was intended to assess how important the groups considered those themes they initially overlooked as compared to the ones which they identified themselves.

The youth group discussions were held in English while the adult and latrine caretakers' discussions were held in the local Ga-Dangme language, though some participants occasionally spoke in English or Akan, Ghana's most popular local language. The youth group discussions were moderated by the lead researcher. For the adult and latrine caretakers' groups, the lead researcher was assisted by a native Ga-Dangme speaker who helped to interpret contributions made in that language between the lead researcher and participants that did not understand either English or Akan. On average, each group discussion lasted for about one hour.

\subsubsection{Household Questionnaire Survey}

Two types of household questionnaires were orally administered. One was administered to households that had access to a latrine at home (either household or shared). Although the JMP defines shared latrines to include those shared at home by two or more households as well as communal or public latrines, we distinguish between the two categories in this paper to reflect the formulation of the post-2015 water and sanitation targets which recognises latrines shared at home and excludes communal latrines (JMP 2013). Shared latrines, in this paper, refer to those shared at home by two or more households while communal or public latrines are those that are open to all persons and may be subject to the payment of a user fee. The term 'private latrines' is used to refer to both household and shared latrines whose use is restricted to specific eligible users.

A total of 88 private latrines were identified using random walks guided by a household database obtained from the Dodowa Health Research Centre, which maintains a demographic and health surveillance system in the study area. For each latrine, the owner of the facility and four other users, namely adult male and female, and a young male and female, were targeted to be respondents. Thus, the number of respondents per latrine ranged between 1 and 5 depending on the sexes and age groups of the users. A total of 189 questionnaires were administered. The questionnaire sought to assess whether the respondents consistently used their private facility or what factors occasionally compelled them to practise open defecation or use a communal latrine.

The other questionnaire was administered to households without access to sanitation at home who are expected to be using communal latrines or practising open defecation. Households were selected from within a $500 \mathrm{~m}$ radius around each of the 7 communal latrines. Thirty nine to 42 households, one per house, were sampled from every other house along a route randomly selected from the latrine location. The questionnaire was administered to one respondent of 18 years or above who volunteered to participate in the study. In all, 283 
questionnaires were administered. This questionnaire sought to establish whether the respondents consistently used the nearest communal latrine and what factors motivated or discouraged them from consistently using the communal latrine.

\subsubsection{Observations}

Observations were made at both private and communal latrines to appreciate the findings of the focus group discussions and questionnaire survey. The user population of communal latrines were also observed through headcounts conducted from 4:00 am to 10:00 pm for seven consecutive days for all seven existing communal latrines.

\subsection{Data Analysis}

Group discussions were recorded in audio format and transcribed. Native Ga-Dangme and Akan speakers translated contributions made in those languages into English. The overall importance of the various themes were compared by calculating the average rank assigned by the various focus groups. The results of the FGDs are presented under the section 'Factors affecting latrine usage identified by focus groups'.

The results of the quantitative survey have been presented under 'Barriers to usage of existing latrines'. Persons who failed to use their respective latrines were marked as 'sanitation defaulters'. Those who had access to private latrines but failed to use them in favour of open defecation or a communal latrine were marked as defaulters of private latrines. Similarly, those who lived within $500 \mathrm{~m}$ of a communal latrine but failed to use them in favour of open defecation were marked as defaulters of communal latrines. Reasons cited for not using sanitation facilities are reported as barriers. Multiple barriers were cited by some respondents. Frequencies of barriers were recorded and their prevalence expressed as a percentage of the total frequencies. Identified barriers were grouped into technical and non-technical categories. Barriers classified as technical are those relating to design and construction but also include operational and maintenance factors that affect technical performance indicators such as odour and fly control. The significance of differences in prevalence of barriers between different categories of respondents, particularly users of household, shared and communal latrines, was tested at $5 \%$ significance level using odds ratios.

Observations made on the average daily user population of the communal latrines were summed up and divided by the total number of cubicles in all the seven communal latrines to obtain the number of users per cubicle as reported in Table 1.

Table 1 Technology options used by households with private latrines

\begin{tabular}{lll}
\hline Technology options & $\begin{array}{l}\text { \% of households with private } \\
\text { latrines using the technology option }\end{array}$ & $\begin{array}{l}\text { \% of all households in Prampram } \\
\text { using the technology option }\end{array}$ \\
\hline Water closet & 28.7 & 4.3 \\
Ventilated Improved Pit (VIP) & 46.7 & 7.0 \\
Pit latrine & 21.3 & 3.2 \\
Pour-flush & 0.8 & 0.1 \\
Bucket latrine & 2.5 & 0.4 \\
Total & 100 & 14.9 \\
\hline
\end{tabular}

\footnotetext{
${ }^{a}$ Not qualified as an improved sanitation facility
} 


\section{Results}

\subsection{Existing Technologies and Their Usage}

\subsubsection{Existing Technology Options}

Table 1 shows the technology options used by households that have access to private latrines at home. Only $15 \%$ of all households in Prampram have access to a private latrine. The ventilated improved pit (VIP) latrine is the most popular sanitation option, used by $47 \%$ of households with private latrines, followed by the water closet and pit latrine that are used by 29 and $21 \%$, respectively. Among the technologies defined as 'improved' by the JMP, the pourflush is the least used, with less than $1 \%$ of households with private latrines using the technology. Although national policy bans the use of the bucket latrine and the conservancy labour system (Jenkins and Scott 2007) for being unhygienic (MLGRD 2010a), it is still used by nearly $3 \%$ of households with private latrines.

All households depend on on-site technologies because no sewerage network exists in the town. Seventy percent of households with private latrines rely on dry sanitation technologies. The predominance of dry technologies was attributed to, among other factors, poor water supply in the town. Some study participants revealed that they could afford the construction of the water closet technology but the poor water supply situation compelled them to adopt the VIP latrine. In one household, it was observed that the existing VIP latrine was converted from a water closet. The septic tank was left in the compound in the hope of converting back to a water closet if water supply improves in the future. Apart from the water supply situation, other reasons stated for the use of the dry technologies (simple pit and VIP) were their relatively lower cost and smaller space requirements.

Users of the water closet technology cited its potential to minimise odour and flies and the prestige accorded to it in the community as their motivation for adopting it, though some users of the technology admitted that it was challenging ensuring that water is always available for flushing. The pour-flush technology, which could be more appropriate due to the small quantity of water it requires, is not common in the community. It was explained by some respondents that they did not know of the technology at the time of constructing their latrines until it was recently adopted in a new communal latrine constructed in the community.

Out of seven communal latrines in the community, one had the water closet technology and another used the pour-flush non-water-seal technology, while the remaining five used the VIP technology.

\subsubsection{Actual Usage of Available Latrines}

Table 2 presents data on the pattern of usage of private and communal latrines by their expected users over the $24 \mathrm{~h}$ before the survey. The table shows the default rates among respondents who had access to private latrines, distinguishing among those who used household and shared latrines, as well as those who had no access at home but lived within $500 \mathrm{~m}$ of a communal latrine.

Although usage of private toilets by the eligible users was found to be high, some users (about $3 \%$ ) defaulted or failed to use their facilities over the previous $24 \mathrm{~h}$. Between users of household and shared latrines the difference in default rates was not statistically significant (odds ratio=1.05; p-value=1). Among 283 residents surveyed who had access to communal latrines only 70 , or about a quarter, actually patronised the nearest communal latrine over the 
Table 2 Usage of private and communal latrines

\begin{tabular}{|c|c|c|c|}
\hline \multirow[t]{2}{*}{ Parameter } & \multicolumn{2}{|c|}{ Private latrines } & \multirow[t]{2}{*}{ Communal latrines } \\
\hline & Household & Shared & \\
\hline Number of latrines sampled & 41 & 47 & 7 \\
\hline Average number of users per cubicle & 3.6 & 9.7 & $18.4^{\mathrm{a}}$ \\
\hline Number of respondents & 61 & 128 & 283 \\
\hline Default rate (\%) over previous $24 \mathrm{~h}$ & $3.3 \%$ & $3.1 \%$ & $75.3 \%$ \\
\hline
\end{tabular}

${ }^{a}$ Based on headcounts conducted at the communal latrines

previous $24 \mathrm{~h}$. Reasons cited for not using private and communal latrines are presented in Table 4.

\subsection{Factors Affecting Latrine Usage Identified by the Focus Groups}

Table 3 presents the factors identified by the focus groups as influencing their decision to use or avoid a particular latrine (whether private or communal) and their relative importance as ranked by the various focus groups.

Nearly all groups ranked safety in terms of protection against structural collapse, falling through the squat hole and entry of reptiles and rodents etc. as the most important factor. Even

Table 3 Factors affecting latrine usage and their relative importance ranked by the focus groups

\begin{tabular}{|c|c|c|c|c|c|c|}
\hline \multirow[t]{2}{*}{ Factors affecting latrine usage } & \multicolumn{6}{|c|}{ Ranking by focus groups } \\
\hline & $\begin{array}{l}\text { Adult } \\
\text { male }\end{array}$ & $\begin{array}{l}\text { Adult } \\
\text { female }\end{array}$ & $\begin{array}{l}\text { Young } \\
\text { male }\end{array}$ & $\begin{array}{l}\text { Young } \\
\text { female }\end{array}$ & $\begin{array}{l}\text { Latrine } \\
\text { caretakers }\end{array}$ & $\begin{array}{l}\text { OVERALL } \\
\text { RANK }\end{array}$ \\
\hline $\begin{array}{l}\text { The user should feel safe using } \\
\text { the latrine in terms of protection } \\
\text { against structural collapse } \\
\text { and entry of reptiles etc. }\end{array}$ & 1 & 3 & 1 & 1 & 1 & 1 \\
\hline $\begin{array}{l}\text { The privacy of the user } \\
\text { should not be exposed }\end{array}$ & $3 / 4$ & $1 / 2$ & 2 & 3 & $2 / 3 / 4$ & 2 \\
\hline $\begin{array}{l}\text { There should be a seat for the } \\
\text { aged/children/disabled etc. }\end{array}$ & 2 & 4 & $3 / 4$ & 2 & $8 / 9$ & 3 \\
\hline $\begin{array}{l}\text { There should be no liquid } \\
\text { discharges from the latrine } \\
\text { that may pollute the } \\
\text { environment }\end{array}$ & $3 / 4$ & $5 / 6 / 7$ & 5 & 4 & $2 / 3 / 4$ & 4 \\
\hline The latrine should be clean & 5 & $1 / 2$ & 6 & 5 & 7 & 5 \\
\hline $\begin{array}{l}\text { There should not be excessive } \\
\text { odour or heat in the latrine }\end{array}$ & 6 & $5 / 6 / 7$ & $3 / 4$ & 8 & $2 / 3 / 4$ & 6 \\
\hline $\begin{array}{l}\text { The latrine should be readily } \\
\text { accessible/available (no long } \\
\text { queues or walking distance) }\end{array}$ & $7 / 8$ & $5 / 6 / 7$ & 7 & 6 & $5 / 6$ & 6 \\
\hline $\begin{array}{l}\text { There should not be many } \\
\text { flies in the latrine }\end{array}$ & 9 & 8 & 8 & 7 & $5 / 6$ & 8 \\
\hline $\begin{array}{l}\text { Hand washing facilities should } \\
\text { be provided }\end{array}$ & $7 / 8$ & 9 & 9 & 9 & $8 / 9$ & 9 \\
\hline
\end{tabular}


Table 4 Barriers to latrine usage reported by respondents of household surveys

\begin{tabular}{|c|c|c|}
\hline Barriers & $\begin{array}{l}\text { Frequency among defaulters } \\
\text { of private latrines }\end{array}$ & $\begin{array}{l}\text { Frequency among defaulters } \\
\text { of communal latrines }\end{array}$ \\
\hline \multicolumn{3}{|l|}{ Technical/technology-related } \\
\hline Intense odour & $7 \%$ & $23 \%$ \\
\hline Pit full (awaiting emptying or unable to empty) & $7 \%$ & - \\
\hline $\begin{array}{l}\text { Latrine closed for chemical application } \\
\text { for sludge reduction }\end{array}$ & $7 \%$ & - \\
\hline Having to squat & $3 \%$ & - \\
\hline No water for flushing & $3 \%$ & - \\
\hline Heat from toilet & - & $3 \%$ \\
\hline Safety & - & $2 \%$ \\
\hline Fly nuisance & - & $1 \%$ \\
\hline All technology-related & $27 \%$ & $29 \%$ \\
\hline \multicolumn{3}{|l|}{ Non-technical } \\
\hline Latrine inaccessible (busy or locked) & $28 \%$ & - \\
\hline Unhygienic condition/poor user habits & $7 \%$ & $7 \%$ \\
\hline Quarrels among users & $7 \%$ & - \\
\hline Sheer preference for defecating in the open & $3 \%-$ & $11 \%$ \\
\hline Distance & - & $28 \%$ \\
\hline User fee & - & $21 \%$ \\
\hline Others & $28 \%$ & $4 \%$ \\
\hline All non-technical barriers & $73 \%$ & $71 \%$ \\
\hline
\end{tabular}

though the adult females ranked cleanliness of the latrine above safety, their explanation showed that they actually valued a clean latrine because of the protection or 'safety' it provides against diseases but not just the sight or convenience of a clean toilet. The provision of hand washing facilities was the least important to nearly all the groups. The actual practice of hand washing was not observed among users of private latrines. For the communal latrines, none of the seven had a functioning hand washing facility. The adult female group explained that the availability of hand washing facilities at communal latrines is not much important to them because they can always wash their hands when they return home after visiting such facilities. In general, no obvious differences were observed in the relative importance assigned to the various factors by the different gender and age groups.

\subsection{Barriers to Usage of Existing Latrines}

Table 4 presents the barriers cited by private and communal latrine defaulters for failing to use their respective latrines. Cited barriers were more related to non-technical than technical factors. For communal latrines, intense odour was the most frequently cited technical barrier. With regard to private latrines, technical barriers mostly resulted from intense odour, desludging challenges and closure of latrines for chemical application to reduce sludge. Although intense odour was cited by defaulters of both communal and private latrines, it was more frequently cited by defaulters of communal latrines $(23 \%)$ than private latrines (7\%). Generally, technical challenges were mostly associated with dry sanitation systems. Non-technical barriers to use of private latrines included the latrine being inaccessible (locked 
or busy) (28 \%) and user-related factors such as unhygienic practices by some users (7\%) and quarrels over cleaning and maintenance responsibilities $(7 \%)$. For communal latrines, the major non-technical barriers cited by respondents were distance to the nearest latrine (28\%), the user fee $(21 \%)$ and unhygienic conditions $(7 \%)$.

\section{Discussion}

\subsection{Appropriateness of Existing Technologies}

The poor water supply situation in the community makes the greater reliance on dry sanitation systems appropriate. For private latrines, the preference for the VIP by many (47 \%) households with private latrines could be attributed to their improved ventilation, hence, their potential to minimise the emission of odour and heat (Ryan and Mara 1983). This preference is consistent with the identification of odour and heat control by the focus groups as a factor that influences latrine usage in the community. Even though the adoption of dry sanitation systems is appropriate, their construction in some cases was not done in line with relevant technical guidelines. For instance, the lengths of vent pipes on some VIP latrines were found to be less than the recommended $500 \mathrm{~mm}$ above flat and sloppy roofs, or up to the highest point on conical roofs (Mara 1984). Inadequate vent height leads to a reduced chimney effect which is the main mechanism for reducing odour and heat in VIP latrines (Ryan and Mara 1983; Mara 1984). Besides, it was observed that some relevant operational guidelines were not followed. For instance, some twin-pit VIP latrines were observed to have both squat holes opened and in use simultaneously. This practice defeats the purpose of pit rotation that allows such latrines to be used continuously (Mara 1984).

For communal latrines, the known poor performance of VIPs under high faecal loading rates makes their use at the communal level inappropriate (MLGRD 2010b). Under high faecal loading rate, the practice of pit rotation (Mara 1984) is not possible since cycle duration becomes too short to allow complete decomposition of excreta for manual removal. Desludging by a cesspit emptier is often not feasible because by the time the pit becomes full, the initial sludge deposits would have partially decomposed and hardened, making it difficult to dislodge by a cesspit emptier. On the other hand, the management of the water closet technology as a communal facility in a water-scarce community could be inefficient and expensive as observed in the study area. In such a case, the pour-flush technology would be most appropriate. Compared to the water closet, the pour-flush uses minimal water, i.e., 1.5-2 litres per flush (Roy et al. 1984; Mara 1985) as compared to nine litres per flush for a standard water closet. Also, unlike a VIP, sludge removal by a cesspit emptier can be easily done since regular flushing prevents the hardening of sludge.

\subsection{Analysis of Latrine Usage Trend}

A comparison of the usage of facilities under different ownership regimes (household, shared and communal latrines) provides some basis for pondering over the JMP's definition of 'improved sanitation' that recognises only facilities that are exclusively used by a single household. According to the JMP, only improved facilities (used by single households) are likely to be used consistently because those who do not have access to improved sanitation facilities are "obliged to defecate in the open or use unsanitary facilities" (JMP 2006; p. 16). However, as shown in Table 2, the default rate among users of household (3.3\%) and shared $(3.1 \%)$ latrines was not statistically significant (odds ratio=1.05; $\mathrm{p}$-value=1). This implies that 
having access to shared facilities at home could achieve as much impact on open defecation as exclusive access by a single household. This finding supports the JMP's emphasis on having access to latrines at home in the formulation of the post-2015 MDG targets on sanitation that prioritises the elimination of open defecation (JMP 2014). Even though the average number of users of shared latrines was higher (9.7) as compared to household latrines (3.6), and could make them more likely to be unhygienic, this risk could be compensated for by the sharing of maintenance costs and cleaning responsibilities among the multiple households. It must, however, be noted that the sharing of latrines by too many households could lead to quarrels among users. It is seen in Table 4 that quarrels among users accounted for $7 \%$ of defaults among users of private latrines.

On the contrary, there was a significantly higher default rate among expected users of communal latrines $(75 \%)$ as compared to users of shared latrines (odds ratio $=3.09$; p-value $<0.0001)$. This confirms the observation that the availability of communal latrines does not necessarily lead to regular latrine usage (Biran et al. 2011). The implication of this finding is that the JMP's definition of improved sanitation is appropriate for excluding communal latrines. For latrines shared at home, it may be more appropriate to consider a limited number of households or a maximum user population per squat hole rather than classifying any level of sharing as unimproved. Another implication of this finding is that the pooling of resources among households for construction of a privately shared facility should be recognised as a potential tool for preventing open defecation and included in latrine promotion messages.

\subsection{Identification of Factors Affecting Latrine Usage}

The factors identified by the focus groups as influencing latrine usage were generally consistent with those identified by other studies such as Appiah and OduroKwarteng (2011), Biran et al. (2011) and Keraita et al. (2013). The frequent mentioning of factors relating to odour and heat emission could be associated with the fact that members of this coastal community have an age-old practice of open defecation on the beaches where they experience unlimited natural ventilation. Therefore, they could be easily irritated by the slightest level of odour and heat encountered in a latrine. This finding implies that technological innovation should pay much attention to increasing the level of ventilation in latrines. However, the high importance attached to privacy implies that efforts to improve ventilation should not lead to provision of wide openings in the superstructure that may compromise the privacy of the user.

A comparison of the findings of the focus group discussions and the household surveys indicate that the most important factors recognised by focus groups as influencing their decision to use or avoid a latrine (safety, privacy and provision of seats for the aged, children and the physically challenged) were adequately catered for by existing latrines in the community. This is seen in the fact that none of the reasons cited by survey respondents for failing to use their latrines related to these important factors. On the other hand, intense odour, desludging challenges and unhygienic conditions which were cited by many defaulters were actually observed in latrines.

\subsection{Potential Interventions to Address Barriers to Latrine Usage}

The barriers to latrine usage in Prampram may be addressed by a combination of technical and non-technical interventions. 


\subsubsection{Potential Technical Interventions}

Figure 1 shows potential technical interventions for overcoming the identified barriers based on literature recommendations and good practices observed in the study area. They are aimed at addressing the fundamental technical challenges that create barriers to latrine usage. For instance, intense odour and heat from pits are often the result of poor ventilation in latrines and may primarily arise from poor design of vent pipes or incorrect positioning of superstructure openings in relation to the direction of wind. These defects were observed in some of the latrines in the community. Ventilation in VIPs as well as fly control may be improved by installing a vent pipe of appropriate dimensions and painting it black to enhance the chimney effect (Ryan and Mara 1983; Mara 1984).

Adoption of wet technologies is particularly recommended for public toilets. Their advantages were attested to by users and managers of a pour-flush public toilet recently constructed in the study area. In addition to their capacity in handling high sludge loads, wet systems with a water-seal have a potential for controlling odour and heat emission as well as minimising fly nuisance. They also eliminate the challenge of hardened sludge which is associated with dry systems. Under the current circumstance where piped water is supplied to the community only once or twice per week, the development of sewerage systems is not feasible. Nevertheless, the pour-flush technology has a high chance of success if a moderate water storage capacity could be maintained.

\begin{tabular}{|c|c|c|}
\hline Interventions & \multicolumn{2}{|l|}{ Barriers } \\
\hline $\begin{array}{l}\text { Install a vent pipe with appropriate } \\
\text { length, diameter and painted black }\end{array}$ & Intense odour & \multirow{5}{*}{ 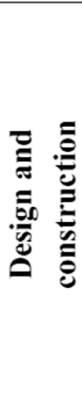 } \\
\hline $\begin{array}{l}\text { Provide screened/perforated lids } \\
\text { for VIP squat holes/seats }\end{array}$ & Heat from toilet & \\
\hline \multirow{2}{*}{$\begin{array}{l}\text { Install insect screens on vent pipes } \\
\text { and superstructure openings }\end{array}$} & Fly nuisance & \\
\hline & \multirow{2}{*}{$\begin{array}{l}\text { Presence of reptiles and } \\
\text { rodents }\end{array}$} & \\
\hline \multirow{2}{*}{$\begin{array}{l}\text { Identify which chemicals require } \\
\text { shortest contact time }\end{array}$} & & \\
\hline & \multirow{2}{*}{$\begin{array}{l}\text { Desludging challenges } \\
\text { (hardened sludge) }\end{array}$} & \multirow{4}{*}{ 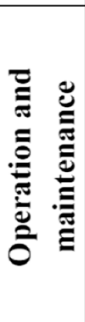 } \\
\hline \multirow{3}{*}{$\begin{array}{l}\text { Adopt a wet technology with } \\
\text { minimal water usage, e.g. pour- } \\
\text { flush } \\
\text { Provide a water-seal for pour-flush } \\
\text { technology }\end{array}$} & & \\
\hline & $\begin{array}{l}\text { Shut down for chemical } \\
\text { application }\end{array}$ & \\
\hline & Lack of adequate water & \\
\hline Provide lighting & Fear of falling into pit & \\
\hline $\begin{array}{l}\text { Provide a seat of an appropriate } \\
\text { height }\end{array}$ & Having to squat & 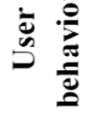 \\
\hline
\end{tabular}

Fig. 1 Technical intervention logic 
Feelings of insecurity among toilet users were associated with the presence of reptiles or rodents in the toilet room and the fear of falling into the pit. Safety could thus be improved by designing the superstructure to prevent entry of rodents and reptiles. For instance, nets or other insect or reptile screens may be fitted on openings in the superstructure, though such openings would need to be enlarged to account for reduced air flow through the nets while maintaining privacy. Another safety measure is providing a squat hole of a maximum width not exceeding $200 \mathrm{~mm}$ (Mara 1984) and providing smaller ones for children in selected cubicles in communal toilets. Safety could also be improved, especially for night users, by installation of a lighting system.

\subsubsection{Potential Non-Technical Interventions}

The large number of private and communal latrine users who cited unhygienic practices by other users as their reason for defaulting the use of their latrines calls for measures to compel owners of private and communal latrines to ensure their hygienic maintenance. In this regard, special attention needs to be given to sanitary inspection in premises, which is one of the key tools for public health regulation emphasised in Ghana's sanitation policy (MLGRD 2010a). In particular, poor management practices of communal toilets such as inadequate cleaning and failure to desludge on time could be improved by public sector regulation and regular monitoring. Furthermore, the establishment of a sanitation information desk at the offices of the local government (District Assembly) to guide households in technology selection and proper construction could lead to the construction of technically appropriate toilets to minimise the technical barriers discussed above. Nevertheless, such an intervention will need to be complimented with initiatives to deal with other socio-economic barriers such as financing, rights over land and the capacity of local artisans. The District Assembly could provide training on proper latrine construction to local artisans and issue them with licenses to operate in the District. A complaint system could then be instituted for feedback and monitoring of performance of artisans.

\section{Conclusions}

Most residents in the Ghanaian peri-urban township depend on dry sanitation systems due to irregular water supply, with the VIP being the commonest technology. Households that have access to private latrines highly patronise them, with shared latrines being no less consistently used than unshared ones as implied by the JMP. This finding makes it imperative to recognise the potential of privately shared latrines in preventing open defecation and to encourage cotenants who cannot afford their own latrines to construct and share facilities. However, our findings support the argument that public latrines do not guarantee regular latrine usage and should remain excluded from the definition of improved sanitation. Nevertheless, they should be provided in public places and in difficult areas where private latrines are not technically feasible for many households.

Residents of Prampram ranked safety and privacy as the most important factors that influence their decision to use or avoid a latrine facility. However, the actual barriers to the use of existing facilities were those relating to odour and heat emission, unhygienic maintenance and lack of immediate access to facilities, which were commonly mentioned in the focus group discussions. Latrine usage in the study setting may be improved by increasing ventilation in latrines to minimise odour and heat emissions. This may require public sector support to households and latrine builders through development of technical guidelines, training and 
information services. For communal latrines, adopting wet technologies with a water-seal and a low water requirement can prevent hardening of sludge and allow easy desluding. The occurrence of unhygienic conditions on both private and communal latrines also calls for domestic sanitary inspection as well as public sector regulation and monitoring of communal latrines to demand their hygienic management.

Acknowledgments The authors wish to acknowledge the Danish International Development Agency for funding their work under the Sustainable Sanitation (SUSA) Ghana research project. The Agency played no direct role in the conduct of the research and the views expressed in this paper do not necessarily reflect its views.

\section{References}

Ampadu-Boakye J, Dotse FM, Laryea NOA, Karikari DY, Gyan E (2011) Improving access to basic sanitation in Ghana: lessons from a water and sanitation project in Ghana. Paper presented at the 3rd Ghana Water Forum: Water and Sanitation Services Delivery in a Rapidly Changing Urban Environment, 5th-7th September, 2011, Accra

Appiah EO, Oduro-Kwarteng S (2011) Households' perception of community toilets in low-income communities in Kumasi. Paper presented at the 3rd Ghana Water Forum: Water and Sanitation Services Delivery in a Rapidly Changing Urban Environment, 5th-7th September, 2011, Accra

Ayele M (2005) Sanitation preference and household latrine designs. A Water Aid Ethiopia Briefing Note No. 1. http://www.wateraid.org/ /media/Publications/sanitation-household-latrine-design-preference-ethiopia.pdf. Accessed 5 July 2014

Biran A, Jenkins MW, Dabrase P, Bhagwat I (2011) Patterns and determinants of communal latrine usage in urban poverty pockets in Bhopal, India. Trop Med Int Health 16(7):854-862

Dittmer A (2009) Towards total sanitation: socio-cultural barriers and triggers to total sanitation in West Africa. WaterAid, London. http://www.wateraid.org/ /media/Publications/total-sanitation-socio-cultural-barrierstriggers-west-africa.pdf. Accessed 10 February 2014

Dodowa Health Research Centre (DHRC) (2012) Demographic and health surveillance system - data file. DHRC, Dodowa

Garfi M, Ferrer-Marti L (2011) Decision-making criteria and indicators for water and sanitation projects in developing countries. Water Sci Technol 64(1):83-101

Ghana Statistical Service (GSS) (2008) Ghana living standards survey: report of the fifth round (GLSS 5). GSS, Accra

Ghana Statistical Service (GSS) (2013) 2010 population and housing census report: millennium development goals in Ghana. GSS, Accra

Jenkins MW, Scott B (2007) Behavioural indicators of household decision-making and demand for sanitation and potential gains from sanitation marketing in Ghana. Soc Sci Med 64:2427-2442

Joint Monitoring Programme (JMP) (2006) Meeting the MDG drinking water and sanitation target: the urban and rural challenge of the decade. WHO and UNICEF, Geneva http://www.who.int/water_sanitation_health/ monitoring/jmpfinal.pdf. Accessed 2 November2013

Joint Monitoring Programme (JMP) (2013) Progress on sanitation and drinking-water: 2013 update. WHO and UNICEF http://www.wssinfo.org/fileadmin/user_upload/resources/JMPreport2013.pdf. Accessed 12 November 2013

Joint Monitoring Programme (JMP) (2014) Progress on sanitation and drinking-water: 2014 update. WHO and UNICEF http://www.wssinfo.org/fileadmin/user_upload/resources/JMP_report_2014_webEng.pdf, Accessed 10 July 2014

Karnib A (2014) A methodological approach for quantitative assessment of the effective wastewater management: Lebanon as a case study. Environ Process 1(4):483-495. doi:10.1007/s40710-014-0032-8

Keraita B, Kjær P, Jensen M, Konradsen F, Akple M, Rheinländer T (2013) Accelerating uptake of household latrines in rural communities in the Volta region of Ghana. J Water Sanit Hyg Dev 03.1:26-34. doi:10.2166/ washdev.2013.035

Kvarnstrom E, McConville J, Bracken P, Johansson M, Fogde M (2011) The sanitation ladder - a need for a revamp? J Water Sanitation Hyg Dev. doi:10.2166/washdev.2011.014

Mara DD (1984) The design of ventilated improved pit latrines. Technology advisory group technical note no. 13. The International Bank for Reconstruction and Development and The World Bank, Washington 
Mara DD (1985) The design of pour-flush latrines. Technology advisory group technical note no. 15. The World Bank, Washington

Mara D, Lane J, Scott B, Trouba D (2010) Sanitation and health. PLoS Med 7(11):e1000363. doi:10.1371/ journal.pmed.1000363

Ministry of Local Government and Rural Development (MLGRD) (2010a) Revised environmental sanitation policy. MLRD, Accra

Ministry of Local Government and Rural Development (MLGRD) (2010b) Guidelines for the provision, operation and maintenance management of public toilets in Ghana. MLGRD, Accra

Nakagawa N, Oe H, Otaki M, Ishizaki K (2006) Application of microbial risk assessment on a residentiallyoperated bio-toilet. J Water Health 4(4):479-486

Olschewski A (2013) TAF (step 2): sanitation - existing - general. http://www.washtechnologies.net/en/taf/tafselection-tool/details/513. Accessed 12 February 2014

Paterson C, Mara D, Curtis T (2007) Pro-poor sanitation technologies. Geoforum 38:901-907

Roy AK, Chatterjee PK, Gupta KN, Khare ST, Rau BB, Singh RS (1984) Manual on the design, construction and maintenance of low-cost pour-flush water seal latrines in India. Technology Advisory Group Technical Note No. 10. The World Bank, Washington

Ryan B, Mara DD (1983) Ventilated Pit latrines: vent pipe design guidelines. Technology Advisory Group Technical Note No. 6. The World Bank, Washington

Sidhu JPS, Toze SG (2009) Human pathogens and their indicators in biosolids: a literature review. Environ Int 35:187-201

Spencer MC (2012) Sanitation practices and preferences in peri-urban Accra, Ghana. Dissertation, Emory University

United Nations Millennium Project (2005) Investing in development: a practical plan to achieve the millennium development goals. United Nations Development Programme http://www.unmillenniumproject.org/ documents/overviewEngLowRes.pdf. Accessed 18 October 2011

Whyte A (1986) Guidelines for planning community participation activities in water supply and sanitation projects. WHO http://whqlibdoc.who.int/offset/WHO_OFFSET_96.pdf. Accessed 5 July 2014 